\title{
Aplicação dos conceitos de sala de aula invertida e suas tecnologias no ensino de ensaios mecânicos: utilização de pré e pós questionários
}

Application of flipped classroom concepts and their technologies in the teaching of mechanical

\author{
tests: use of pre and post questionnaires
}

Aplicación de conceptos de aula invertida y sus tecnologías en la enseñanza de pruebas mecánicas: uso de cuestionarios pre y post

Recebido: 22/05/2021 | Revisado: 30/05/2021 | Aceito: 02/06/2021 | Publicado: 16/06/2021

Sinval Pedroso da Silva
ORCID: https://orcid.org/0000-0002-3622-3308
Instituto Federal de Educação, Ciência e Tecnologia de Minas Gerais, Brasil
E-mail: sinval.pedroso@ifmg.edu.br
Bruna Aparecida Rezende
ORCID: https://orcid.org/0000-0003-1930-2589
E-mail: bruna.rezende@ifmg.edu.br
Fernanda Palladino
Instituto Federal de Educação, Ciência e Tecnologia de Minas Gerais, Brasil
ORCID: https://orcid.org/0000-0003-4233-8053
Universidade Federal de Minas Gerais, Brasil
E-mail: ferpalladino12@gmail.com

\begin{abstract}
Resumo
O conceito de sala de aula invertida e o uso de tecnologias baseadas na internet vêm sendo usados em diversas áreas do conhecimento como métodos alternativos à metodologia tradicional. Este conceito engloba um método de aprendizagem ativa, no qual o aluno faz a internalização dos conteúdos essenciais antes da aula e depois discute e interage com o professor, esclarecendo as dúvidas. Diante disso, este trabalho teve como objetivo analisar a evolução dos modelos mentais de estudantes do curso técnico subsequente em mecânica de uma instituição federal brasileira, referente ao tópico de ensaios mecânicos, visando diagnosticar eventuais lacunas conceituais do desenvolvimento do conhecimento. Foi utilizada a análise quantitativa por meio de questionários, aplicados antes e após o conteúdo ministrado em sala de aula. O experimento foi realizado com amostra aleatória de $\mathrm{n}=13$ estudantes, e teve o intuito de fazer uma análise comparativa entre os participantes. De acordo com os resultados obtidos, o percentual de acerto antes e após ministrar o conteúdo foi de $33,85 \%$ e $69,23 \%$, respectivamente, o que justifica que as pontuações dos alunos no questionário pós foram mais altas em relação ao questionário prévio. Este fato constata que a sala de aula invertida ou ensino híbrido pode levar a um melhor desempenho acadêmico dos estudantes. Este trabalho permitiu também detectar lacunas de aprendizagem, as quais não seriam possíveis serem identificadas por meio de avaliações tradicionais, possibilitando um aperfeiçoamento do processo de ensino e aprendizagem, com base em um planejamento didático mais eficaz.
\end{abstract}

Palavras-chave: Ensaios mecânicos; Ensino-aprendizagem; Ensino híbrido; Modelos mentais.

\begin{abstract}
The concept of inverted classrooms and the use of internet-based technologies has been used in several areas of knowledge as alternative methods to the traditional methodology. This concept encompasses an active learning method, in which the student internalizes the essential contents before class and then discusses and interacts with the teacher, clarifying doubts. Therefore, this work aimed to analyze the evolution of the mental models of students of the subsequent technical course in mechanics from a Brazilian federal institution, referring to the topic of mechanical tests, to diagnose any conceptual gaps in the development of knowledge. Quantitative analysis was used through questionnaires, applied before and after the content was taught in the classroom. The experiment was carried out with a random sample of $\mathrm{n}=$ 13 students, and intended to make a comparative analysis between the participants. According to the results obtained, the percentage of correct answers before and after teaching the content was $33.85 \%$ and $69.23 \%$, respectively, which justifies that the students' scores in the post questionnaire were higher in comparison to the previous questionnaire. This fact finds that the flipped classroom or hybrid teaching can lead to better students' academic performance. This work also made it possible to detect learning gaps, which would not be possible to be identified through traditional assessments, enabling an improvement of the teaching and learning process, based on a more effective didactic planning. Keywords: Hybrid teaching; Mechanical tests; Mental models; Teaching-learning.
\end{abstract}




\section{Resumen}

El concepto de aula invertida y el uso de tecnologías basadas en Internet se han utilizado en varias áreas del conocimiento como métodos alternativos a la metodología tradicional. Este concepto engloba un método de aprendizaje activo, en el que el alumno interioriza los contenidos esenciales antes de la clase y luego discute e interactúa con el docente, aclarando dudas. Por tanto, este trabajo tuvo como objetivo analizar la evolución de los modelos mentales de los estudiantes del curso técnico en mecánica de una institución federal brasileña, en el tema de las pruebas mecánicas, para diagnosticar las brechas conceptuales en el desarrollo del conocimiento. Se utilizó el análisis cuantitativo a través de cuestionarios, aplicados antes y después del contenido impartido en el aula. El experimento se llevó a cabo con una muestra aleatoria de $\mathrm{n}=13$ estudiantes, y tuvo como objetivo realizar un análisis comparativo entre los participantes. Según los resultados obtenidos, el porcentaje de aciertos antes y después de impartir el contenido fue de 33,85\% y $69,23 \%$, respectivamente, lo que justifica que las puntuaciones de los alumnos en el post cuestionario fueron superiores en relación al cuestionario anterior. Este hecho encuentra que el aula invertida o la enseñanza híbrida pueden conducir a un mejor rendimiento académico de los estudiantes. Este trabajo también permitió detectar brechas de aprendizaje, que no serían posibles de identificar a través de evaluaciones tradicionales, permitiendo una mejora del proceso de enseñanza y aprendizaje, a partir de un plan didáctico más efectivo.

Palabras clave: Aprendiendo-enseñando; Enseñanza híbrida; Modelos mentales; Pruebas mecánicas.

\section{Introdução}

O interesse em métodos alternativos sobre o processo de ensino-aprendizagem, além da metodologia tradicional, tem aumentado na área da educação, dentre os quais o projeto de sala de aula invertida e o uso de tecnologias utilizando a internet. Neste aspecto, existem algumas definições disponíveis na literatura sobre sala de aula invertida. De acordo com Felder; Brent (2009), a sala de aula invertida é qualquer atividade relacionada ao curso que todos os alunos em uma aula são convidados a fazer, além de simplesmente assistir, ouvir e fazer anotações de forma passiva. Conforme Baepler; Walker; Driessen (2014), sala de aula invertida é um projeto de aprendizagem que altera a divisão de atividades do aluno, combinando tempo de sala de aula presencial com instruções online. Para Låg; Sæle (2019) a sala de aula invertida é um modelo de ensino que move a maior parte da instrução centrada no professor para fora da sala de aula, possibilitando ao professor ter mais tempo para se dedicar às atividades de aprendizado com foco no aluno durante a aula. Outros autores, como Bishop (2013), enfatiza a utilização de tecnologias digitais, alguns descrevem a importância de usar uma abordagem pedagógica particular como aprendizagem colaborativa. Nota-se que, apesar das divergências sobre a definição, existe consenso que sala de aula invertida trata-se de um método de aprendizagem ativa. Conforme Kim et al. (2014), os princípios de projeto recomendados para a sala de aula invertida inclui: oferecer uma oportunidade para que os alunos obtenham informações preliminares antes da aula; oferecer um melhor benefício na própria experiência de aprendizagem do aluno em ambientes online e em sala de aula, o que inclui tecnologias instrucionais eficazes e sustentáveis que apoiem as respectivas estratégias de inversão.

Esse conceito de sala de aula invertida pode desempenhar um papel significativo no processo de aprendizagem híbrida, para o qual existem várias teorias, dentre elas, as que defendem que uma determinada porcentagem do curso, por exemplo $50 \%$ ou mais, deve ocorrer online, para que o curso seja considerado híbrido. Conforme Moran (2015), acontecem vários tipos de educação híbrida: de saberes e valores, quando integra-se várias áreas de conhecimento (no modelo disciplinar ou não); de metodologias, com desafios, atividades, projetos, jogos, grupais e individuais, colaborativos e personalizados. Também fala-se de tecnologias híbridas, que integram as atividades da sala de aula com as digitais, as presenciais com as virtuais. Híbrido implica em misturar e integrar áreas diferentes, profissionais diferentes e alunos diferentes, em espaços e tempos diferentes.

De acordo com Moran (2017), é necessário realizar mudanças para quebrar os modelos estabelecidos, capacitar coordenadores, professores e alunos para trabalharem mais com metodologias ativas, com currículos mais flexíveis, com inversão de processos, tais como aplicar primeiro atividades online e depois atividades em sala de aula. Conforme Camillo; Vargas; Medeiros (2018), o ensino híbrido, além de inovador, já vem mostrando vários resultados positivos.

A sala de aula invertida ou aprendizagem híbrida podem ser consideradas como um dos métodos para identificar os modelos mentais, pois, de acordo com Bergmann \& Sams (2016), são capazes de produzir impacto positivo na educação, uma 
vez que a aprendizagem está nas mãos dos alunos, e não nas mãos dos professores, contribuindo assim para que a verdadeira aprendizagem ocorra com mais eficácia.

Os modelos mentais são concebidos como uma estrutura cognitiva que fundamenta o raciocínio, a tomada de decisões e, com as limitações de atitudes e comportamentos também observados na literatura. Para Sousa (2017), o cérebro humano coleta informações sobre o mundo e o organiza para formar uma representação desse mundo. Essa representação, ou modelo mental, descreve o pensamento ou um processo que um indivíduo humano usa para funcionar naquele mundo. De acordo com JohnsonLaird (1983), modelos mentais oferecem uma teoria unificada das principais propriedades da mente, as quais são: compreensão, inferência e consciência. Conforme Jones et al. (2011), os modelos mentais fornecem o mecanismo pelo qual novas informações são filtradas e armazenadas, sendo que estes modelos são construídos por indivíduos, com base em suas experiências de vida pessoal, percepções e entendimentos do mundo. Isso inclui o processo de aprendizagem, para o qual, Amaral (2007) afirma que as diversas teorias que discutem os estilos de aprendizagem podem ser observadas em três momentos do processamento da informação: recepção, seleção / organização e utilização.

Neste aspecto, existem diversos modelos de estilos de aprendizagem, os quais são padrões comuns de preferências do aluno para diferentes abordagens de ensino, com certos atributos - comportamentos, atitudes, pontos fortes e fracos - sendo associados a cada preferência (Felder, 2020). De acordo com Felder (2020); Felder \& Silverman (1988); Felder \& Soloman (1993), os tipos de estilos de aprendizagem correspondem à aprendizes: ativos e reflexivos; sensíveis e intuitivos; visuais e verbais; sequenciais e globais. Cada uma dessas categorias tem associado a ela certas habilidades características, as quais são importantes para o sucesso da maioria das profissões.

Desta forma, os saberes e experiências prévias, contribuem para a análise de problemas e para a tomada de decisões. Esta afirmação corrobora as informações de Lüdke \& André (1986), que a mente humana é altamente seletiva, e que duas pessoas enxergam diferentes coisas à partir do olhar para um mesmo objeto ou situação. A história pessoal e a bagagem cultural influenciam o que cada pessoa seleciona para ver, fazendo com que se concentrem em determinados aspectos da realidade em detrimento aos demais.

De acordo com Mateus (2019), existem alguns motivos pelos quais os estudantes não conseguem construir modelos significativos próximos ao conceitual para determinados assuntos, dentre os quais, está relacionado a não existência de modelos prévios de alguns conceitos importantes. Existe também evidências do importante papel do professor no processo de ensino e aprendizagem, pois, observa-se a não consideração desses modelos prévios dos estudantes nas práticas pedagógicas. Como resultado, acabam se tornando obstáculos para a aprendizagem nesse processo reversível, simultâneo e dinâmico. Considerando o modelo de aulas tradicionais, esta situação e, os respectivos modelos mentais sobre o tema, acabam sendo identificados tardiamente, apenas no período das avaliações.

Diante desse contexto, este trabalho teve como objetivo principal identificar e analisar a evolução dos modelos mentais de alunos do curso técnico subsequente em mecânica de uma instituição federal brasileira, referente ao tópico de ensaios mecânicos, da disciplina tecnologia dos materiais, para diagnosticar eventuais lacunas conceituais do desenvolvimento do conhecimento. Este curso é destinado aos alunos que já possuem o ensino médio completo e possui duração de dois anos, equivalente a quatro módulos (um por semestre). O experimento foi realizado com amostra aleatória de treze $(\mathrm{n}=13)$ estudantes do segundo módulo, e consistiu em questionários pré e pós, sobre o tópico de ensaios mecânicos da disciplina de tecnologia dos materiais, e possibilitou fazer uma análise comparativa entre os pesquisados. Essa disciplina é considerada obrigatória e essencial para o técnico em mecânica, aborda conteúdos técnicos, dentre os quais o tópico de ensaios mecânicos; essencial por apresentar os principais ensaios e possíveis falhas mecânicas de materiais e componentes. 


\section{Metodologia}

Foi utilizado neste trabalho o tipo de pesquisa qualitativa e quantitativa, as quais de acordo com Yin (2001) não se excluem, e portanto, podem se complementar e permitir um melhor entendimento dos fenômenos em estudo. A metodologia de pesquisa utilizada foi experimental, por meio da aplicação de questionários como instrumentos de coleta de dados. Conforme Köche (2011), a experimentação é a fase em que o cientista realiza os experimentos sobre o problema investigado, para poder observar e registrar metódica e sistematicamente as informações coletadas.

Os questionários foram planejados, desenvolvidos e aplicados nos meses de março e abril de 2021, os quais possuem questões fechadas, que abordam o conhecimento dos alunos do curso técnico subsequente em mecânica, referente ao conteúdo de ensaios mecânicos. Essas questões possibilitam quantificar o número e percentual de acerto de cada respondente referente ao conteúdo ministrado.

O experimento foi realizado com amostra aleatória de treze $(n=13)$ estudantes do segundo módulo do curso técnico subsequente em mecânica, de uma instituição federal brasileira, os quais cursaram a disciplina de tecnologia dos materiais. O trabalho teve o intuito de fazer uma análise comparativa entre os participantes, identificar e classificar a evolução de seus modelos mentais. Os questionários foram aplicados antes e após o conteúdo ser ministrado em sala de aula, denominados pré-teste e pósteste, respectivamente. Cada questionário possui cinco (5) questões, cada uma com valor de $20 \%$, as quais englobam o nível de conhecimento dos estudantes sobre o tópico de ensaios mecânicos. Os questionários foram elaborados com questões de caráter múltipla escolha, sem consulta, permitindo apenas uma tentativa e duração máxima de 20 minutos, os quais foram disponibilizados e corrigidos em plataforma global adotada pela instituição de ensino. Os dados foram analisados com base no nível de dificuldade, previamente definido e categorizado para cada questão, sendo: duas questões de nível fácil; uma de nível médio, e duas questões de nível difícil.

A seguir estão apresentadas as questões aplicadas no pré-teste e os respectivos níveis de dificuldade.

Questão 1) Analise a Figura que mostra as curvas de tensão-deformação de três materiais distintos e assinale a alternativa correta. - (NÍVEL FÁCIL).

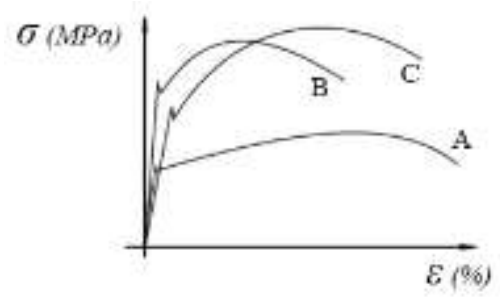

a) O material B possui o maior limite de resistência à tração.

b) O material A possui o maior limite de resistência à tração.

c) O material C possui o maior limite de resistência à tração.

d) O material $\mathrm{C}$ possui menor limite de resistência à tração comparado com o material $\mathrm{B}$.

Questão 2) Analise as afirmativas a seguir. - (NÍVEL MÉDIO).
(A) Dureza Brinell
(B) Dureza Vickers
(C) Dureza Rockwell

(1) o penetrador é uma esfera de aço temperado ou de tungstênio.

(2) penetradores do tipo esférico ou cônico. 
(3) pirâmide de base quadrada.

Marque a opção que relaciona corretamente os itens anteriores.

a) A-1, B-2, C-3.

b) A-1, B-3, C-2.

c) A-2, B-3, C-1.

d) A-3, B-2, C-1.

Questão 3) Referente ao limite de proporcionalidade obtido nos ensaios de tração de materiais, é correto afirmar apenas que. (NÍVEL DIFÍCIL).

a) A lei de Hooke só é válida até um determinado valor de tensão, denominado limite de proporcionalidade.

b) Após o limite de proporcionalidade, a deformação passa a ser proporcional à carga aplicada.

c) É equivalente ao limite de resistência à tração do material.

d) É equivalente ao limite de ruptura do material.

e) Nenhuma das alternativas.

Questão 4) As formas usuais de aplicação de tensão podem ser, exceto. - (NÍVEL FÁCIL).
a) Tração.
b) Impacto.
c) Compressão.
d) Cisalhamento.
e) Torção.

Questão 5) Com relação à fadiga, as afirmativas a seguir estão corretas, exceto. - (NÍVEL DIFÍCIL).

a) A curva S-N apresenta a relação entre a amplitude de tensão e o número de ciclos até a falha de um material.

b) Fadiga é a aplicação de cargas ou deformações variáveis por um período de tempo.

c) O limite de fadiga aumenta em função da adição de um raio de adoçamento (geometria e com maior raio do entalhe).

d) O limite de fadiga diminui com o melhor acabamento superficial

e) As propriedades em fadiga dos materiais é determinada a partir de ensaios de simulação em laboratório.

O questionário pós foi também aplicado com base em duas questões de nível fácil, uma questão de nível médio e duas questões de nível difícil, as quais estão apresentadas a seguir, com o respectivo nível de dificuldade.

Questão 1) Os ensaios mecânicos permitem obter informações rotineiras do produto e também possibilita desenvolver novas informações sobre os materiais; no desenvolvimento de novas ligas e novos processos de fabricação, tais como novos tratamentos. Os ensaios mecânicos podem ser classificados em, exceto. - (NÍVEL FÁCIL).

a) Destrutivos, os quais provocam a inutilização da peça ou componente

b) Não destrutivos, os quais não comprometem a integridade da peça

c) Estáticos, com carga aplicada lentamente

d) Tração, compressão e dureza, os quais representam as formas de obtenção de tensão

e) Dinâmicos, com carga aplicada rapidamente ou ciclicamente 
Questão 2) Analise as afirmativas e a Figura que mostra as curvas típicas do ensaio de tração e marque a alternativa incorreta. (NÍVEL MÉDIO).

(I) é uma curva típica para aços de alta resistência.

(II) é uma curva para aços de baixo a médio carbono.

(III) é uma curva típica para ferro fundido cinzento.

(IV) é uma curva para materiais muito maleáveis como o latão e o cobre.

(V) apenas as opções (I) e (III) estão corretas

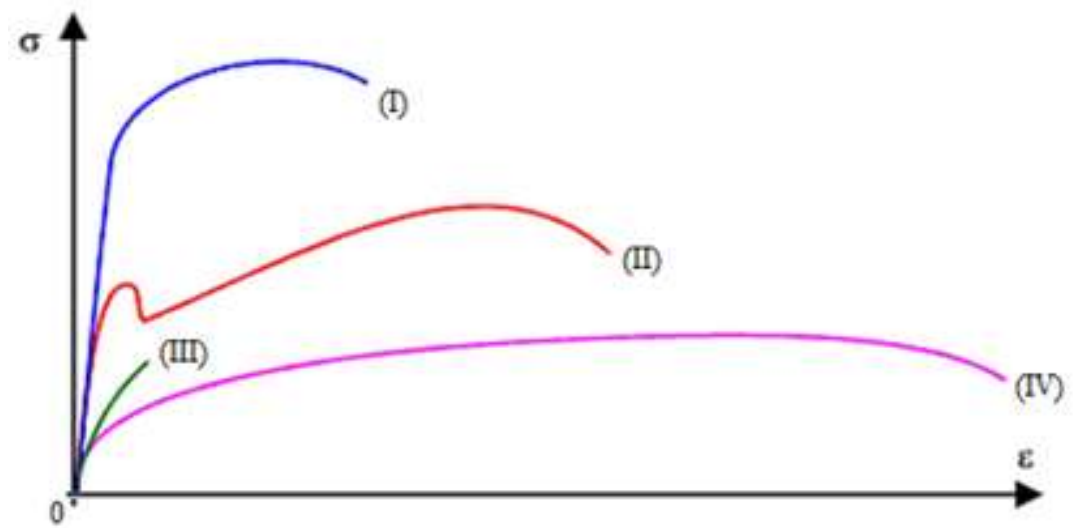

Questão 3) A Figura mostra o efeito do tipo de material na curva S-N, a qual representa a amplitude de tensão alternada em função do número de ciclos até a falha, que é obtida por ensaios de fadiga. Marque a alternativa incorreta. - (NÍVEL DIFÍCIL).

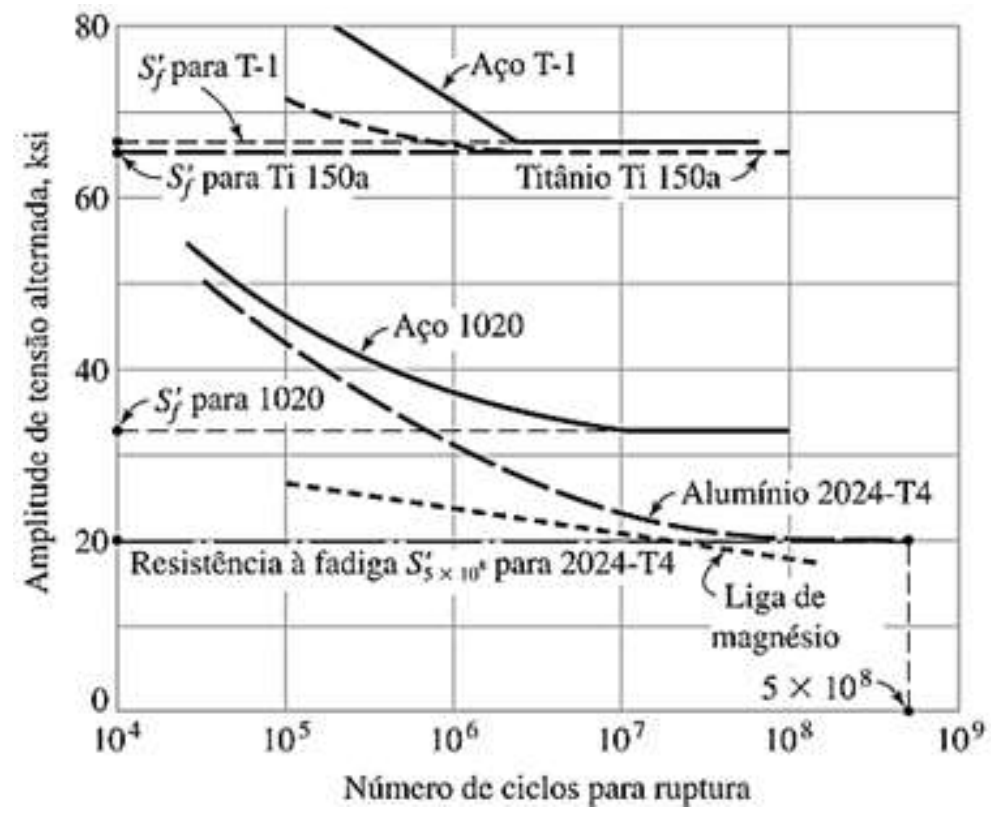

Fonte: Collins; Busby; Staab (2010).

a) Os aços e o titânio apresentam limites de resistência à fadiga bem definidos.

b) O titânio Ti 150a apresenta limite de resistência à fadiga inferior em relação ao aço T-1, porém, à 70 ksi apresenta número de ciclos para a falha maior em relação ao aço T-1.

c) Os metais não ferrosos em geral, como o alumínio e suas ligas, não apresentam limites de resistência à fadiga bem definidos.

d) A formação do cotovelo (articulação) para aços e titânio situa-se entre $10^{6}$ a $10^{7}$ ciclos e corresponde ao ponto do gráfico que indica o limite de resistência à fadiga para vida infinita. 
e) O limite de resistência à fadiga para o aço 1020 corresponde a aproximadamente $33 \mathrm{ksi}$.

Questão 4) Dureza é uma medida da resistência de um material a deformação plástica localizada. Com base neste aspecto, são métodos de dureza mais usuais. Marque a(s) opção(s) correta(s): - (NÍVEL FÁCIL).
a) Dureza Brinell
b) Dureza Vickers
c) Dureza Rockwell
d) Dureza Knoop

Questão 5) Analise as afirmativas referente a realização do ensaio de tração e marque as opções corretas. - (NÍVEL DIFÍCIL).

a) O ensaio tem por finalidade determinar o limite de resistência à tração.

b) O ensaio tem por finalidade determinar o diâmetro do material ensaiado.

c) O ensaio tem por finalidade determinar a impressão causada por um penetrador.

d) O ensaio tem por finalidade determinar o alongamento do corpo de prova ensaiado.

e) Na realização do ensaio pode ocorrer deformações elástica e plástica, respectivamente, na sequência em que os fenômenos ocorrem no material.

f) Na realização do ensaio pode ocorrer deformações plástica e elástica, respectivamente, na sequência em que os fenômenos ocorrem no material.

g) Na realização do ensaio pode ocorrer deformações elástica e regular, respectivamente, na sequência em que os fenômenos ocorrem no material.

Os alunos foram convidados a responder os questionários antes do conteúdo ser ministrado em sala de aula (pré-teste) e após (pós-teste). O pré-teste mediu o nível de conhecimento geral prévio dos alunos sobre o tema de ensaios mecânicos. O pósteste abrangeu o mesmo tema e teve o mesmo nível de dificuldade do que o pré-teste, porém abordou diferentes questões além de ter sido aplicado três (3) semanas após ter sido ministrado o conteúdo em aula. O formato de múltipla escolha foi empregado para ambos os testes. Desta forma, foi definido o método de comparação direta das pontuações do pré-teste com o pós-teste, pois, os testes tiveram os mesmos níveis de dificuldade, apesar de terem sido realizados em diferentes momentos. Os questionários foram desenvolvidos e aplicados por meio de uma plataforma de comunicação e colaboração, a qual é uma ferramenta global e no formato de conexão com a internet.

\section{Resultados e Discussão}

O tipo de pesquisa utilizada neste trabalho foi qualitativa, pois, de acordo com (Estrela, 2018), explica a realidade em termos de conceitos, comportamentos e percepções. Outro tipo de pesquisa utilizada foi a quantitativa, pois, conforme Pereira et al. (2018), os métodos qualitativos podem muitas vezes se transformar em investigações quantitativas, por meio do emprego de questões fechadas, com dados obtidos por meio da aplicação de questionários.

A pesquisa foi desenvolvida com os alunos do curso técnico em mecânica, modalidade subsequente. É importante destacar que em relação ao pós-teste, duas questões apresentaram mais de uma alternativa como correta. Dessa forma, caso o aluno tenha acertado pelo menos uma alternativa, considerou-se que o mesmo alcançou a nota referente a questão.

Primeiramente, optou-se por apresentar os resultados referentes ao pré-teste e pós-teste, separadamente. Ao final, uma comparação é realizada para análise, partindo da comparação dos dois questionários utilizados. Foi realizada uma análise qualitativa dos dados e os mesmos podem ser verificados na Tabela 1. Nota-se que a tabela mostra a nota individual de cada 
aluno, a porcentagem de acerto e a porcentagem de cada aluno em relação à média da turma, assim como a média da turma.

Tabela 1. Nota dos alunos, média global da turma, porcentagem de acerto e porcentagem em relação à média da turma, obtidas no questionário prévio.

\begin{tabular}{cccccccc}
\hline ALUNO & Q1-F & Q2-M & Q3-D & Q4-F & Q5-D & $\begin{array}{c}\text { ACERTOS } \\
(\%)\end{array}$ & $\begin{array}{c}\text { \% em relação à média } \\
\text { da turma }\end{array}$ \\
\hline 1 & 0 & 1 & 0 & 1 & 0 & 40 & 118,18 \\
2 & 0 & 0 & 0 & 1 & 0 & 20 & 59,09 \\
3 & 0 & 1 & 0 & 1 & 1 & 60 & 177,27 \\
4 & 1 & 1 & 0 & 0 & 0 & 40 & 118,18 \\
5 & 1 & 1 & 1 & 1 & 0 & 80 & 236,36 \\
6 & 0 & 0 & 1 & 0 & 0 & 20 & 59,09 \\
7 & 0 & 0 & 0 & 1 & 0 & 20 & 59,09 \\
8 & 1 & 1 & 0 & 1 & 0 & 60 & 177,27 \\
9 & 0 & 1 & 0 & 0 & 0 & 20 & 59,09 \\
10 & 0 & 1 & 0 & 1 & 0 & 40 & 118,00 \\
11 & 0 & 0 & 0 & 0 & 0 & 0 & 0 \\
12 & 0 & 0 & 0 & 1 & 0 & 20 & 59,09 \\
13 & 0 & 0 & 0 & 0 & 1 & 20 & 59,09 \\
\hline Soma & $\mathbf{3}$ & $\mathbf{7}$ & $\mathbf{2}$ & $\mathbf{8}$ & $\mathbf{2}$ & $\mathbf{4 4 0 , 0 0 \%}$ & \\
\hline & & & & & Média & $\mathbf{3 3 , 8 5 \%}$ & \\
\hline
\end{tabular}

${ }^{1}$ Nível de dificuldade: Q1-F = Fácil; Q2-M = Médio; Q3-D = Difícil; Q4-F = FÁCIL; Q5-D = Difícil Fonte: Autores (2021).

Pode-se observar que a turma obteve uma média de 33,85 \%, o que indica um baixo conhecimento acerca do tema proposto. Por meio da comparação individual de cada aluno em relação à média da turma, pode-se observar que trata-se de uma turma heterogênea, sendo que seis alunos se posicionaram acima da média e sete alunos não atingiram a média geral. Com relação às questões, o maior número de acertos (8) foi obtido para uma das questões fáceis, e o menor número de acertos (2) para as questões difíceis. Nota-se também que houve um resultado atípico, pois, foi obtido o maior número de acertos para a questão 2, que é de nível médio (7), em relação à questão 1, de nível fácil (3).

Notou-se que alguns alunos já traziam algum nível de conhecimento prévio a respeito do tópico de ensaios mecânicos, pois, obtiveram resultados no pré-teste de $60 \%, 80 \%$ e $80 \%$, respectivamente, como observado nos alunos 3 , 5 e 8. Isso é justificado pois os alunos já trabalham em indústrias ou em oficinas mecânicas. Entretanto, para outros alunos o assunto foi totalmente novo, evidenciando assim o desnível entre os discentes, os quais parte acabam se sentindo inibidos de participar ativamente nas aulas, apesar da abertura proporcionada por muitos professores.

A Tabela 2 mostra os resultados obtidos após o desenvolvimento do conteúdo ministrado de ensaios mecânicos. 
Tabela 2. Nota dos alunos, média global da turma, porcentagem de acerto e porcentagem em relação à média da turma, obtidas no questionário após a apresentação do conteúdo.

\begin{tabular}{cccccccc}
\hline ALUNO & Q1-F & Q2-M & Q3-D & Q4-F & Q5-D & $\begin{array}{c}\text { ACERTOS } \\
(\%)\end{array}$ & $\begin{array}{c}\text { \% em relação à média } \\
\text { da turma }\end{array}$ \\
\hline 1 & 0 & 0 & 1 & 0 & 1 & 40 & 57,78 \\
2 & 1 & 1 & 1 & 0 & 1 & 80 & 115,56 \\
3 & 1 & 1 & 1 & 1 & 1 & 100 & 250,00 \\
4 & 1 & 1 & 1 & 1 & 1 & 100 & 250,00 \\
5 & 1 & 1 & 1 & 0 & 1 & 80 & 115,56 \\
6 & 0 & 0 & 1 & 1 & 1 & 60 & 86,67 \\
7 & 1 & 1 & 1 & 1 & 1 & 100 & 144,44 \\
8 & 1 & 0 & 1 & 1 & 1 & 80 & 115,56 \\
9 & 0 & 0 & 1 & 0 & 1 & 40 & 57,78 \\
10 & 0 & 0 & 1 & 0 & 1 & 40 & 57,78 \\
11 & 0 & 1 & 1 & 0 & 1 & 60 & 86,67 \\
12 & 1 & 0 & 1 & 0 & 0 & 40 & 57,78 \\
13 & 1 & 0 & 1 & 1 & 1 & 80 & 115,56 \\
\hline Soma & $\mathbf{8}$ & $\mathbf{6}$ & $\mathbf{1 3}$ & $\mathbf{6}$ & $\mathbf{1 2}$ & $\mathbf{9 0 0 , 0 0 \%}$ & \\
\hline & & & & & Média & $\mathbf{6 9 , 2 3 \%}$ & \\
\hline
\end{tabular}

Fonte: Autores (2021).

A média geral obtida pela turma no questionário disponibilizado após ministrar o conteúdo foi de 69,23\%, que é superior à média obtida para o questionário prévio (33,85 \%), indicando que houve uma evolução do aprendizado pelos alunos. Partindo-se da análise da Tabela 2, observa-se que a turma se manteve heterogênea, porém, nove (9) alunos se posicionaram na média, ao passo que os outros quatro (4) alunos não atingiram a média.

Partindo-se de uma análise mais individual, observa-se que o aluno 1 se limitou a acertar questões de nível fácil e médio primeiramente; contudo, no questionário pós obteve algum progresso com relação ao seu modelo mental, acertando duas questões de nível difícil. Já o aluno 2 apresentou um modelo mental precário no questionário prévio, se limitando a acertar apenas uma questão de nível fácil. Porém, no questionário pós obteve um progresso considerável, errando apenas uma questão. O aluno 3 teve um rendimento médio no questionário prévio e acertou todas as questões do questionário pós, tendo um rendimento significativamente satisfatório. O aluno 4 evoluiu seu desempenho, tendo acertado todas as questões do questionário pós. O aluno 5 conseguiu acertar todas as questões difíceis e errou apenas uma questão em ambos os questionários. O aluno 6 se destacou em termos de evolução de modelo mental. No questionário prévio acertou apenas uma questão de nível difícil. Por outro lado, no questionário pós acertou todas as questões difíceis. O aluno 7 se destacou em termos de evolução de modelo mental, frente ao conteúdo de ensaios mecânicos, pois seu resultado no questionário prévio foi o acerto de apenas uma questão de nível fácil e, em contrapartida, acertou todas as questões do questionário pós. O aluno 8 conseguiu evoluir seu desempenho, acertando questões de nível médio a fácil no questionário pré, e questões difíceis no questionário pós. O aluno 9 acertou questões de nível 
difícil no questionário pós, ao contrário do acerto de apenas uma questão de nível médio no pré-teste. O aluno 10 obteve resultados semelhantes aos do aluno 1. O aluno 11 se destacou em termos de evolução de modelo mental, pois o mesmo não acertou nenhuma questão no questionário prévio, no entanto, acertou três questões (de nível médio e difícil) no questionário pós. O aluno 12 demonstrou evolução do seu modelo mental, visto que conseguiu acertar uma questão difícil a mais no questionário pós em relação ao pré-teste. O aluno 13 acertou uma questão difícil no pré-teste, entretanto, acertou duas questões fáceis e duas difíceis no pós-teste, justificando que houve significativa evolução do seu modelo mental.

Nota-se que após o experimento, as pontuações dos alunos no pós-teste foram mais altas em relação ao pré-teste. Isso corrobora o trabalho de Foldnes (2016) que constatou que a sala de aula invertida, se implementada corretamente com a aprendizagem cooperativa, pode levar a um melhor desempenho acadêmico.

A Figura 1 mostra o número de acertos obtidos para cada questão de ambos os questionários (pré e pós). Observa-se que houve evolução dos modelos mentais dos alunos sobre o conteúdo de ensaios mecânicos, pois, os alunos foram capazes de desenvolver e aumentar o nível de conhecimento sobre o assunto abordado. Com exceção da questão 2, na qual os alunos obtiveram menor número de acertos no pós-teste (6) em relação ao pré-teste (7), nota-se uma pequena discrepância em relação às demais questões. O maior número de acertos, para ambos os questionários, foi obtido na questão 4, de nível fácil.

Figura 1. Número de acertos por questão obtidos pelos alunos nos questionários pré e pós.

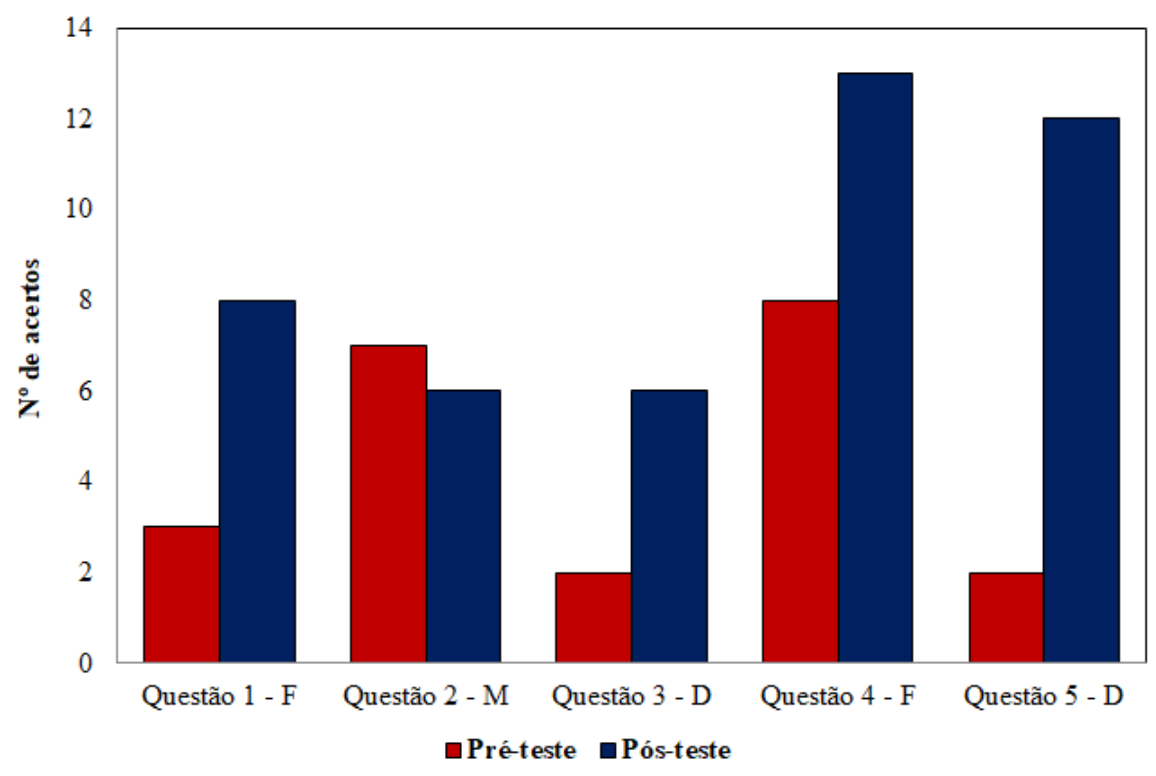

Fonte: Autores (2021).

Com base nos resultados obtidos no questionário (pré-teste), ficou constatado que os modelos mentais dos alunos são consideravelmente heterogêneos. Foi possível observar o amadurecimento e evolução dos modelos mentais dos alunos, por meio dos questionários pré e pós o conteúdo ministrado. Os resultados obtidos neste trabalho corroboram os dados obtidos por Silva; Costa; Martins (2020), visto que foram similares. Os autores avaliaram os modelos mentais dos alunos do segundo ano de um curso técnico em manutenção automotiva, referente ao tópico sistemas de arrefecimento, e constataram que os modelos mentais dos alunos são significativamente heterogêneos. O uso de questionários, pré e pós o assunto ministrado, mostraram-se eficientes em diagnosticar o amadurecimento e a evolução dos modelos mentais dos alunos. Assim como relatado por Foldnes (2016), que observou que as pontuações dos alunos em um questionário pós e também no exame final foram mais altas para um grupo de alunos da classe invertida em relação a um grupo de controle que recebeu as aulas tradicionais. O autor concluiu que a sala de aula invertida, se implementada corretamente com a aprendizagem cooperativa, pode levar a um melhor desempenho acadêmico 
e um método de ensino mais eficaz em relação ao formato tradicional de aula-lição de casa.

Considerando a metodologia utilizada para o desenvolvimento do conteúdo referente a ensaios mecânicos, buscou-se desenvolver diferentes estratégias, recursos e modelos conceituais que proporcionam aos alunos subsídios para a construção, bem como a evolução dos seus modelos mentais, de acordo com o previsto por Santos; Melo; Andrade (2015). Nota-se que um dos princípios da modalidade de ensino híbrido ou sala de aula invertida, foi aplicada no desenvolvimento deste trabalho. Vale ressaltar que os alunos tiveram a oportunidade de ter acesso à algumas informações preliminares, referentes ao conteúdo programado, antes da aula ser ministrada pelo professor.

Além disso, a atual situação de ensino remoto emergencial (E.R.E), devido a pandemia do COVID-19, acelerou o processo de aprendizagem híbrida, pois, parte das aulas são síncronas (com o professor ao vivo com os alunos) e parte assíncrona (com atividades sem a presença do professor). Ambas as aulas são realizadas com o uso de tecnologias e plataformas digitais baseadas na internet, e contribuem para o processo de ensino-aprendizagem.

Outro ponto importante é que a aplicação de questionário pré, possibilita aos alunos aguçar o interesse pelo conhecimento, motivando-os a prestarem mais atenção nas aulas, fazendo questionamentos a respeito do conteúdo, contribuindo assim para a melhoria do seu aprendizado. Isso vai de encontro com o descrito por Moran (2015), que a aprendizagem é mais significativa quando os alunos são motivados intimamente, quando eles acham sentido nas atividades que são propostas, quando suas motivações profundas são consultadas, quando se engajam em projetos criativos e socialmente relevantes, de forma a serem internalizados pelos próprios alunos.

\section{Considerações Finais}

Com base nos resultados obtidos neste trabalho, foi possível descrever as seguintes considerações:

Nota-se um maior número de acertos nas questões do pós-teste ( $69,23 \%)$ em relação ao pré-teste $(33,85 \%)$, o qual foi aplicado antes de ministrar o conteúdo. Isso mostra que houve uma evolução conceitual dos alunos, indicando que o conteúdo foi ministrado de forma correta e que o ensino híbrido promove uma aprendizagem mais orientada nos alunos e com foco na pesquisa, trazendo mais responsabilidade e independência, contribuindo para a melhoria do desempenho acadêmico.

A aplicação de questionário pré, possibilitou aos alunos aguçar o interesse pelo conhecimento, motivando-os a prestarem mais atenção nas aulas, fazendo questionamentos a respeito do conteúdo, contribuindo assim para a melhoria do seu aprendizado. Isso indica que a metodologia utilizada neste trabalho, mostrou-se eficaz em motivar os alunos, especialmente neste período atual de ensino remoto emergencial (E.R.E.), utilizado por diversas instituições de ensino em função da pandemia de COVID19. Isso é justificado pelos melhores resultados obtidos pelos alunos no pós-teste em relação ao pré-teste.

Visto que a metodologia utilizada, bem como o material didático foram os mesmos para todos os alunos, sugere-se, como trabalho futuro, a análise sobre os diferentes estilos de aprendizagem. Sugere-se que o diagnóstico dos principais modelos encontrados poderá contribuir para a melhoria do ensino-aprendizagem de cada aluno, de forma que os mesmos possam assimilar mais rapidamente o conteúdo ensinado.

\section{Agradecimentos}

Os autores agradecem ao Instituto Federal de Educação, Ciência e Tecnologia de Minas Gerais (IFMG), Brasil, pela oportunidade em desenvolver este trabalho.

\section{Referências}

Amaral, V. L. (2007). Estratégias e estilos de aprendizagem: a aprendizagem no adulto. UFRN - Universidade Federal do Rio Grande do Norte. http://www.ead.uepb.edu.br/arquivos/cursos/Geografia_PAR_UAB/Fasciculos - Material/Psicologia_Educacao/Psi_Ed_A09_J_GR_20112007.pdf. 
Baepler, P., Walker, J. D., \& Driessen, M. (2014). It's not about seat time: blending, flipping, and efficiency in active learning classrooms. Computers \& Education, 78, 227-236. https://doi.org/10.1016/j.compedu.2014.06.006.

Bergmann, J., \& Sams, A. (2016). Sala de aula invertida: uma metodologia ativa de aprendizagem (1st ed.). LTC - Livros Técnicos e Científicos.

Bishop, J. L. (2013). DigitalCommons @ USU A Controlled Study of the Flipped Classroom With Numerical Methods for Engineers.

Camillo, C. M., Vargas, M. E. G., \& Medeiros, L. M. (2018). Ensino híbrido: a sala de aula invertida como possibilidade de en sino e aprendizagem. $3^{\circ}$ ELPED e $4^{\circ}$ ELICPIBID-Encontro de Licenciaturas e PIBID Do Sudoeste Goiano.

Collins, J. A., Busby, H., \& Staab, G. (2010). Mechanical design of machine elements and machines: a failure prevention perspective (2nd ed.). John Wiley \& Sons, Inc.

Estrela, C. (2018). Metodologia científica: ciência, ensino, pesquisa (3ª). Editora Artes médicas.

Felder, R. M. (2020). Opinion: uses, misuses, and validity of learning styles. Advances in Engineering Education, 8(1), 1-14.

Felder, R. M., \& Brent, R. (2009). Active learning: an introduction. ASQ Higher Education Brief, 2(4).

Felder, R. M., \& Silverman, L. K. (1988). Learning and teaching styles in engineering education. Engineering Education, 78(7), 674-681.

Felder, R. M., \& Soloman, B. A. (1993). Learning styles and strategies (pp. 107-109). www.ncsu.edu/felder-public/Learning_Styles.html.

Foldnes, N. (2016). The flipped classroom and cooperative learning: evidence from a randomised experiment. Active Learning in Higher Education, 17(1), 3949. https://doi.org/10.1177/1469787415616726.

Johnson-Laird, P. N. (1983). Mental Models: towards a cognitive science of language, inference, and consciousness. Harvard University Press.

Jones, N. A., Ross, H., Lynam, T., Perez, P., \& Leitch, A. (2011). Mental Models : An Interdisciplinary Synthesis of Theory and Methods. Ecology and Society, $16(1)$.

Kim, M. K., Kim, S. M., Khera, O., \& Getman, J. (2014). The experience of three flipped classrooms in an urban university: an exploration of design principles. The Internet and Higher Education, 22, 37-50. https://doi.org/10.1016/j.iheduc.2014.04.003.

Köche, J. C. (2011). Fundamentos de metodologia científica: teoria da ciência e iniciação à pesquisa. Editora Vozes. https://doi.org/10.1590/S151797022003000100005 .

Låg, T., \& Sæle, R. G. (2019). Does the flipped classroom improve student learning and satisfaction? A systematic review and meta-analysis. American Educational Research Association (AERA), 5(3), 1-17. https://doi.org/10.1177/2332858419870489.

Lüdke, M., \& André, M. E. D. . (1986). Métodos de coleta de dados: observação, entrevista e análise documental. In L. A. Faustini (Ed.), Pesquisa em educação: abordagens qualitativas (pp. 25-44). EPU. https://edisciplinas.usp.br/pluginfile.php/4091392/mod_resource/content/1/Lud_And_cap3.pdf.

Mateus, P. G. (2019). Levantamento de modelos mentais para verificação de aprendizagem significativa do conceito de equilíbrio químico em licenciandos em química. Universidade Federal de São Carlos (UFSCar).

Moran, J. (2015). Educação híbrida : um conceito chave para a educação, hoje. In T. \& T. Bacich (Ed.), Ensino Híbrido: personalização e tecnologia na educação (pp. 27-45). PENSO - Grupo A.

Moran, J. (2017). Metodologias ativas e modelos híbridos na educação. In S. Yaegashi (Ed.), Novas Tecnologias Digitais: reflexões sobre mediação, aprendizagem e desenvolvimento (CRV, pp. 23-35). https://doi.org/10.24824/978854441989.2.

Pereira, A., Shitsuka, D., Parreira, F., \& Shitsuka, R. (2018). Metodologia da pesquisa científica. [free e-book]. Núcleo de Tecnologia Educacional (NTE) da Universidade Federal de Santa Maria (UFSM).

Santos, A. C. O., Melo, M. R., \& Andrade, T. S. (2015). Identificando modelos mentais de equilíbrio químico: uma alternativa para a melhoria do processo de ensino e aprendizagem. Revista Fórum Identidades, 18(mai-ago).

Silva, V. A. da, Costa, R. C., \& Martins, V. L. (2020). Identificação dos modelos mentais sobre sistemas de arrefecimento dos alunos do curso técnico em manutenção automotiva. Research, Society and Development, 9(11), 1-16. https://doi.org/10.33448/rsd-v9i11.9554.

Sousa, D. A. (2017). How the brain learns (Fifth). Corwin.

Yin, R. K. (2001). Estudo de caso: planejamento e métodos $\left(2^{\mathrm{a}}\right)$. Bookman. 